\title{
TOWARDS A LINGUISTIC MODEL OF SENTENCE DEVELOPMENT IN WRITING
}

\begin{abstract}
:
Drawing on the findings of an ESRC-funded research study, which included a detailed linguistic analysis of a large corpus of writing from secondary English classrooms, this article describes patterns of linguistic deployment at the level of the sentence. Given the limited number of applied linguistic studies which consider writing development in older writers, as opposed to primary aged writers, the paper aims to investigate developmental differences in mastery of the sentence in this older age group. It describes similarities and differences in linguistic characteristics of writing at sentence level according to age and to writing ability, and makes connections between the linguistic patterns and effectiveness in writing. The paper illustrates that clear developmental trajectories in writing can be determined which have implications for appropriate pedagogical or instructional designs. Finally, the paper offers a linguistic model of sentence development in writing, and signals the potential significance of linguistic models within a multi-disciplinary approach to writing pedagogy.
\end{abstract}

Key words: linguistic development; grammar; writing; sentence development; writing design

Sharples (1999), drawing on both socio-cultural and psychological paradigms, has argued that we should conceptualise writing as creative design, an act of deliberate shaping, imposing meaning through lexical and linguistic choices. This argument has been developed by Maun and Myhill (2005), showing how teenage writers are acutely conscious of both visual and verbal aspects of writing, and positing the view that not only should we theorise writing as an act of design, but that we should also theorise writers as designers. The notion of design incorporates the management of the cognitive writing processes of idea generation and text production, within a framework which acknowledges that writing is a social practice, requiring understanding of implied readers and the nature of genres as communicative discourses. Linguistic competence is central to both the cognitive and the social aspects of writing, as writers need not only to become confident producers of language outputs, but also confident shapers of text to suit audience and purpose. However, the discipline of linguistics has been slow to address itself to development of competence in writing, or to the linguistic experiences of learners becoming writers. Kress (1994:3) critiques linguistics for not providing the theoretical and methodological tools either for the analysis of writing ... or for the analysis and understanding of the developmental processes and stages in the learning of writing' whilst Collins and Gentner (1980:53) argue for 'a linguistic theory of good structures for sentences, paragraphs, and texts' which would have 'direct implications for the teaching of writing'.

Indeed, despite an extensive corpus of research on text linguistics, there is relatively little systematic exploration of the linguistic characteristics of children's writing, and limited attempts to describe development. The term 'writing development' is, as Applebee (2000:92) notes, an ambiguous one: 'it can refer to the ordinary developmental course of learning to write, or to the systematic (or less so) curriculum or program of instruction for developing those skills'. In psychology, models of writing development tend to focus on describing the development of cognitive writing processes (see, for example, Berninger and Swanson 1994), whereas psychodynamic models of writing development pursue 'an interest in the mind of the writer at work' (Arnold 
1991:5). In contrast to prevailing psychological, socio-cultural or literary perspectives on writing development, Kress (1994) aimed to provide a 'linguistic account' of learning to write, illustrating the transition in young children from speaking and reading, to writing.

Kress suggests that 'the sentence belongs to writing' (1994:7): in moving from oral utterances to graphic representations, the young writer has to develop an understanding of the sentence as a written unit which differs from the chained utterances of speech, with their false starts, hesitations and repetitions. The work of Perera (1984) and Kress (1994) is seminal in their analyses of how young writers learn how to design sentences with increasing sophistication. Kress found that the early grasp of sentence is as a textual unit, not a syntactical unit, frequently carrying information and meaning which in a more mature writer would be developed in a paragraph. Each sentence often contains a discrete idea, and early writing is characterized by frequent use of co-ordination and clausal chaining. Perera argued that, with increasing age, children use more subordinate clauses and a wider variety of clause types, and move from predominantly active verbs to the greater use of passives and modals. Both Kress and Perera maintain that temporal indicators are also common in the writing of younger children, including 'when' subordinate clauses, particularly when writing narrative. Narrative is often ordered by the sequence of events, but non-narrative writing creates more problems because the writer has to determine in what order to put the facts. This kind of writing requires a different level of control, and frequently young children's writing or immature writing is characterised by sentence units which may contain facts but no obvious order to those facts. In Bereiter and Scardamalia's (1987) explication of the difference between novice and expert writers, this chaining of information at sentence level is termed the knowledge-telling phase: more expert writers who develop the ability to operate a mental dialogue between content and rhetoric are at a knowledge-transforming phase.

Two earlier studies in the US attempted to define development in terms of the sequence in which syntactic structures in sentences were acquired. Hunt's (1965) study analysed a range of sentence features in children's writing at three different age levels: sentence length, clause length and subordination ratio, as well as withinclause structures such as nominals, and predicate adjectives. He found that the structures he studied 'are virtually all used by fourth graders and are used often enough and successfully enough to indicate that fourth graders command them' and concluded that there was 'no justification for teaching some structures early and others late' (Hunt 1965: 155). This was, however, a very small-scale study involving only one sample of writing from 18 children at each age level. Loban's (1976) longitudinal study followed a larger sample of 211 children through from kindergarten to Grade 12 and found that sentences and subjects became longer, and that embedded structures increased with age. Applebee (2000:97) argues that these, and other, attempts to find 'a developmental sequence of syntactic structures ... eventually failed', suggesting instead that linguistic development is marked not by the acquisition of new structures but 'by the student's ability to manage an increasing degree of structural complexity - that is, to include more structures effectively within a single sentence'.

In learning to achieve effective structural complexity in the linguistic unit of the sentence, young writers have to learn to manage the difference between speech and writing. That writing is linguistically more integrated than speech is well-understood. Czerniewska (1992) notes that writing contains more complex structures, more 
subordination, more premodification, more participial subordination, and greater lexical density than speech. Speech, on the other hand, has more repetition and chaining. However, the way that different writers variously shape and craft meaning at the level of the sentence has been less systematically explored. In writing, it is syntactical alteration which allows the writer to signal the significant, and to direct the reader to the most important information. Spoken language has less of this variety because importance can be signalled in different ways: the speaker is able to vary the rhythm, speed and volume of delivery and to place the intonation nucleus anywhere in the clause' (Perera 1984:187). A consequence of this is that repetitive sentence structures in speech are often not noticed, whereas in writing 'these paralinguistic and prosodic features are absent, so monotony of grammatical structure is thrown into prominence' (Perera 1984:187). Loban (1976) suggested that oral and written language development were closely aligned, with patterns in writing tending to mirror similar patterns in oral language which had occurred approximately a year earlier.

However, research appears a little unsure about the precise developmental relationship between speech and writing, and about how thoughts are transformed into written sentences. Linguistics is well able to describe how syntactic structures can influence the communication of meaning at the level of the sentence. Mapping sentences in terms of theme and rheme, and the principle of linearization where 'what the writer puts first will influence the interpretation of everything that else that follows' (Brown and Yule 1983: 133) are familiar ideas to linguists. So too is the idea of end focus in a sentence (Leech and Svartvik 1975): because the last word or clause in a sentence receives more emphasis, expert writers will alter word order to direct the reader's attention to the important information through using the passive, or through inversion, clefting or fronting. These are design choices which the developing writer has to learn to manage and they are choices which require awareness, be it implicit or explicit, that a written sentence is not the same as a spoken utterance. Indeed, for some children learning to write, the discrepancy between their oral patterns and dialects and the expectations and conventions of Standard written English means they have 'a particularly demanding adjustment to make' (Perera 1984:213) in moving from talk to written sentences. Kress notes that syntactically the speech of professional classes is closer to the syntax of writing than for many other social groups 'whose dialects are little if at all influenced by the structure of writing' (Kress 1994:3).

What is evident is that 'writing models remain unclear concerning the formulation of sentences' (Alamargot and Chanquoy 2001:76) and that there is 'little research specifically on written sentence production' (Cleland and Pickering 2006:186), particularly in the secondary phase of schooling (aged 11-16). Both Perera and Kress focus on primary writers, and Perera acknowledges that 'knowledge about the later stages of acquisition is slight in comparison with the considerable amount of information that has been accumulated about the first three years' (1984:12). A recent study in the UK (QCA 1999; Myhill 1999) analysed linguistic patterns in writing in the public examinations of English (GCSE) taken at age 16, and compared patterns of performance in writing at different achievement levels. This comparison of children of the same age but of differing writing competence appears to be unique: all previous studies of linguistic development have taken age as the key variable in development, rather than attainment in writing. That writing development is not simply chronological is partially addressed by Berninger, Fuller and Whittaker (1996) who propose that development is dynamic, with linear development occurring 'across the life span' and horizontal development occurring as 'expertise is expanded to new genres' 
(1996:15). However, their work is principally concerned with cognitive processes and has little to offer a theory of linguistic development. It was the goal of this study to conduct an empirical enquiry which explicitly focused on linguistic development in secondary school writers.

\section{Methodology:}

The data reported here is drawn from a two year study funded by the Economic and Social Research Council. The first stage comprised a detailed analysis at sentence and text level of a sample of children's writing, whilst the second stage developed the findings from this analysis through observing children writing in the classroom and conducting post hoc interviews with them. The interviews used the writing undertaken in the lesson and the observation to explore children's understanding of their own writing processes and the linguistic choices they made. The methodological rationale and research design was deliberately constructed to enable connections to be made between linguistics and education: Hudson (2004) has argued that applied linguistics research has not always provided 'accessible descriptions of relevant language systems' for practitioners and policy-makers to use: it was the intention of this study to redress this deficit. Linguistic processing in writing is a meaning-making activity, in which developing writers draw variously on their linguistic and cultural resources to communicate. Accordingly, the linguistic analysis in this study combined both quantitative exploration of linguistic features with qualitative investigations of effect and meaning-making. An over-arching aim of this study was to conduct research which, as Lagemann (2002) argues, generates usable knowledge which is applicable, transmissible, embodied in professional practice, and which has the potential to make a difference.

The first stage of the study was a systematic desk analysis of writing samples for their linguistic characteristics at sentence and text level, building on an earlier project conducted for the Qualifications and Curriculum Authority (QCA 1999), itself a development of the Massey et al (1996) study which had examined GCSE examination writing over time. The sample of 718 pieces of writing for stage 1 was drawn from six schools in order to secure the necessary stratification by year group, gender and writing achievement. The writing sample was taken from classes using written work which had been marked against national criteria. In year 8 (13 year olds), the writing was awarded a National Curriculum level - these levels are a set of national descriptors of achievement which are not age-related but attainment-related and are used to determine achievement from age 5 to 14 . In year 10 , a General Certificate of Secondary Education (GCSE) grade: the GCSE is the national qualification for 16 year olds in England and Wales. The sample was stratified by gender, year group and the assessment grade awarded to the writing: in year 8, the sample comprised levels 4, 5 and 6; and in year 10 comprised grades $A^{*} / A, B / C$, and $D / E$. The writing was marked first by the class teachers and the Project Director read each piece of writing as a final check on the accuracy of levels/grades awarded. These grades and levels were used as a proxy for the quality of writing. It needs acknowledgement, however, that the notion of 'quality' in writing is not uncontested, and these gradings represent quality as determined by current national assessment criteria and professional judgment.

Each writing sample was word-processed for ease of analysis. Two coding frames were used: a Paragraph and Textual Organisation Coding Framework was applied to the whole text and involved making coding judgments about paragraphing and text structure, and a Sentence Level Coding Framework, adapted from one used in a 
previous research study for the Qualifications and Curriculum Authority (QCA 1999). It is the results of the latter coding which forms the basis for this paper. Theoretically, the study draws on the linguistic model proposed by Quirke et al (1985). The sentence level analysis was conducted upon a sample of 100 words from each piece of writing: detailed sentence level analysis of the whole text would have been too time-consuming to conduct on a large sample but the practice of Massey et al (1996) of using just one sentence from each text was deemed to narrow. The selection of 100 words began at the first sentence after the thirtieth word in order to avoid any bias which might be incurred through using the opening sentences. In a small number of cases, where the writing sample was very brief, the 100 words had to be taken slightly earlier in the writing. As the study was interested in grammatical structures not accuracy in punctuation, any omitted full stops were inserted so that the sentence counts accurately captured the grammatical sentences created by the writer. Qualitative examples of linguistic structures were collected as well as counts, and an open-ended response box allowed for qualitative comments on the texts.

\begin{tabular}{|c|c|c|}
\hline \multicolumn{2}{|c|}{ Sentence Length } & Illustrative Examples (where appropriate) \\
\hline $\begin{array}{l} \\
\square \\
\square \\
\square \\
\square\end{array}$ & $\begin{array}{l}\text { Number of sentences } \\
\text { Number of words in shortest sentence } \\
\text { Number of words in longest sentence } \\
\text { Minor sentences }\end{array}$ & He was late again. $\underline{A \text { disaster. }}$ \\
\hline \multicolumn{3}{|l|}{ Clauses } \\
\hline \multicolumn{2}{|r|}{$\begin{array}{ll} & \text { Number of finite verbs } \\
\square & \text { Number of finite subordinate clauses } \\
\square & \text { List of subordinators used } \\
\square & \text { Number of coordinate clauses } \\
\square & \text { List of co-ordinators used } \\
\square & \text { Non-finite clause: } \\
> & \text { Infinitive } \\
> & \text { Present participle } \\
> & \text { Past participle }\end{array}$} & $\begin{array}{l}\text { He wanted to leave by ten o'clock. } \\
\text { Blushing furiously, the girl retrieved her dignity! } \\
\text { Exhausted from the effort, they sank on to their beds }\end{array}$ \\
\hline \multicolumn{3}{|c|}{ Sentence Openings } \\
\hline $\begin{array}{l}\square \\
\square \\
\square \\
\square \\
\square \\
\square\end{array}$ & $\begin{array}{l}\text { Subject } \\
\text { Adverbial (phrases) } \\
\text { Non-finite clause } \\
\text { Finite subordinate clause } \\
\text { Fronting } \\
\text { Cleft sentence }\end{array}$ & $\begin{array}{l}\text { The table was covered with good food } \\
\text { Later, we realized it was mistaken identity. } \\
\text { Turning round slowly, she revealed her face to him. } \\
\text { When I had finished eating, I went straight to bed. } \\
\text { His face I didn't like, but his character I despise } \\
\text { It was Jane who took the prize }\end{array}$ \\
\hline \multicolumn{3}{|c|}{ Syntactical structures } \\
\hline $\begin{array}{l}0 \\
\square \\
\square\end{array}$ & $\begin{array}{l}\text { Subject Verb inversions } \\
\text { Subject clauses }\end{array}$ & $\begin{array}{l}\text { Down came the rain. } \\
\text { That he argued was a shame. }\end{array}$ \\
\hline
\end{tabular}

Table 1: coding categories used.

The coding was undertaken by the Project Director and two linguists. The three coders undertook careful piloting and training prior to beginning the coding process to ensure coder reliability and a batch of 30 scripts were 
double-coded to allow a further check on coder reliability. A purpose-designed database was created for the coding data, and statistical analysis undertaken using the Statistical Package for Social Scentists (SPSS). The collation of examples in the database, and the qualitative response sheets allowed further qualitative analysis of features and exemplification of the findings.

\section{Findings of the Study:}

In order to make the presentation of statistical data as accessible as possible, the data below will be presented in the same format and layout, where feasible. The tabular data will generally display the differences between the good, average and weak writing in the sample, and where important, comparisons between year 8 and year 10 will also be shown. The tables will indicate the means and the statistical significance data and all statistically significant results will be indicated with an asterisk.

\section{Sentence length and patterning:}

\begin{tabular}{|c|c|c|c|}
\hline & & means & statistical significance \\
\hline \multirow{5}{*}{$\begin{array}{l}\text { Number of words } \\
\text { per sentence }\end{array}$} & good & 18.2 & \multirow[t]{3}{*}{0.483} \\
\hline & average & 17.4 & \\
\hline & weak & 17.5 & \\
\hline & yr 8 (all) & 17.4 & \multirow[t]{2}{*}{$0.020^{*}$} \\
\hline & yr10 (all) & 18.0 & \\
\hline \multirow{5}{*}{$\begin{array}{l}\text { Number of words } \\
\text { in longest } \\
\text { sentence }\end{array}$} & good & 28.15 & \multirow[t]{3}{*}{$0.011^{*}$} \\
\hline & average & 27.70 & \\
\hline & weak & 26.80 & \\
\hline & yr 8 (all) & 26.78 & \multirow[t]{2}{*}{$0.025^{\star}$} \\
\hline & yr10 (all) & 28.61 & \\
\hline \multirow{5}{*}{$\begin{array}{l}\text { Number of words } \\
\text { in shortest } \\
\text { sentence }\end{array}$} & good & 9.71 & \multirow[t]{3}{*}{0.083} \\
\hline & average & 8.85 & \\
\hline & weak & 8.71 & \\
\hline & yr 8 (all) & 8.64 & \multirow[t]{2}{*}{$0.029^{*}$} \\
\hline & yr10 (all) & 9.54 & \\
\hline \multirow{5}{*}{$\begin{array}{l}\text { Loss of control of } \\
\text { longest sentence } \\
\text { (expressed as \% of } \\
\text { the variable) }\end{array}$} & good & $2.9 \%$ & \multirow[t]{3}{*}{$0.01^{*}$} \\
\hline & average & $6.7 \%$ & \\
\hline & weak & $11.3 \%$ & \\
\hline & yr 8 (all) & $5.0 \%$ & \multirow[t]{2}{*}{0.059} \\
\hline & yr10 (all) & $8.9 \%$ & \\
\hline
\end{tabular}

Table 2: showing differences in sentence length

In line with Loban's (1976) finding that sentence length increased with age, there was a statistically significant difference in sentence length between year 8 and year 10 writers, but no significant differences in mean sentence length in writing produced by writers at different levels of writing achievement. The analysis also revealed that not only do able writers produce longer longest sentences, but weaker writing presents a higher proportion of sentences in which the writer was judged to have lost control of the sentence, either through grammatical inaccuracy or through poor management of the ideas expressed. There were no statistically significant patterns 
between good, average or weak writing in the length of the shortest sentences or the use of minor sentences, but the shortest sentence tended to be longer in year 10 than year $8(p=0.029)$.

The qualitative analysis of sentence length and patterning provided further illumination of these data and highlighted patterns not revealed by the statistics: in particular, there were qualitative differences between writers of differing writing ability. The most able writers appeared to be using short or minor sentences to craft an effect, such as drawing attention to a key idea, or using a series of short sentences to create a staccato effect complementing the tension of the narrative line, as can be seen in the two examples below.

Ignorance is bliss. Apparently. Not so when you are sat staring out of a window at a gorgeous spring day, but with no clue as to the conversations going on around you, and no indication that anyone wants you included at all. As I gaze intently at the blue-sky horizon my thoughts drift, away from a room where I am so obviously unwanted, un-needed, to an entirely different situation.

What would happen if I did rest? Surely a quick gasp of refreshing air couldn't hurt, could it? No, I didn't dare stop. They were behind me, and rapidly gaining distance.

The qualitative analysis also shows that able writers often used contrasting sentence lengths, sometimes juxtaposing a short sentence with a very long one or vice versa, as in the two examples below.

My brain had switched into an autopilot mode while everything around me was a blank. But I was focused.

To be honest, I hated Kenya! The clothes we wore became sodden with sweat after a matter of minutes; the sun cream was failing dismally (scarlet patches were erupting on my shoulders and I couldn't resist scratching the back of my neck) and also the fruit my mum had packed into my bag was crushed into the sort of mush commonly found in a pig's trough.

In contrast, the variation in sentence length evident in average writing appeared to have less strong design purposes and to achieve no particular effects:

A few years ago my brother, mum, dad and I went on a family holiday to Ibiza in July. We were on a beach. Everyone was tired and frustrated in the sweltering heat. The sea was warm and the sand hot. My brother had just bought some new trainers in a local shop so he was happy, running around. Later on, after we had been on the beach for approximately one hour, hunger started to strike. We were discussing what we should do for lunch.

Similarly, for weak writers, there appeared to be little purpose to the deployment of short or long sentences, and moreover, the longest sentence was more likely to be confused and poorly managed. A clear distinguishing feature of weak writing was the lack of confidence controlling and managing ideas within a long sentence. 
The fear about euthanasia is that some people may be persuaded into euthanasia through bad advice or by fealing that they are a burden to the family or society, with that many doctors, nurses and other people believe that every life has hope and that any life is better than no life at all.

The insights offered here from both the quantitative and qualitative data indicate that able writers have greater confidence in using the length of the sentence as a means to reinforce their communicative message. They were better able to use short sentences for effect, to juxtapose and contrast sentences of different length, and to convey complex ideas coherently in long sentences.

\section{Clause types:}

The analysis of clause types presents a pattern of development which is contrary to that in younger writers, where the use of subordination develops with age and attainment in writing. In this research, focusing on secondary-age writers, better writers used fewer finite subordinate and co-ordinate clauses than average or weak writers, with one corresponding implication being that good writing is characterised by the presence of more simple sentences, or by less chaining of clauses within one sentence than less accomplished writing. Indeed, the presence of both subordinate and co-ordinate clauses decreases with increasing quality and is statistically significant.

\begin{tabular}{|c|c|c|c|}
\hline Per 100 words & & Mean & $\begin{array}{l}\text { Statistical } \\
\text { significance }\end{array}$ \\
\hline \multirow[t]{3}{*}{ Number of finite verbs } & good & 12.15 & \multirow{3}{*}{$0.000^{*}$} \\
\hline & average & 12.90 & \\
\hline & weak & 14.18 & \\
\hline \multirow{3}{*}{$\begin{array}{l}\text { Number of finite } \\
\text { subordinate clauses }\end{array}$} & good & 3.99 & \multirow{3}{*}{$0.022^{*}$} \\
\hline & average & 4.25 & \\
\hline & weak & 4.53 & \\
\hline \multirow{3}{*}{$\begin{array}{l}\text { Number of co-ordinated } \\
\text { clauses }\end{array}$} & good & 2.25 & \multirow{3}{*}{$0.000^{*}$} \\
\hline & average & 2.71 & \\
\hline & weak & 3.18 & \\
\hline
\end{tabular}

Table 3: Differences in subordination and co-ordination

In the best pieces of writing, the relatively lower use of subordination and co-ordination frequently reflected a facility for shaping sequences of sentences to reinforce the meaning conveyed, and is linked with the patterning of long and short sentences discussed in the previous section. In the extract below, a year 10 boy, writing an argument that the model, Jordan, is paid too much, uses rhetorical patterning to make his point. Three questions with subordinate clauses are followed by the one word minor sentence 'No', before he highlights in a statement sentence the real reason for Jordan's high pay: 
Is it because she makes music that truly touches millions of people? No. Is it because she writes beautiful, thought-provoking novels? No. Is it because she paints stunning pictures? No. It is purely the fact that she has huge breasts.

Of course, not all the good writers demonstrated this level of sophistication, but the tendency to use simple sentences alongside those with subordination or coordination was a strong tendency, as exemplified below:

I didn't mean to seem ungrateful for your presents. When I found the new curtains I felt cheated. You had taken part of my individuality. I know you were just trying to give me a surprise, but I felt like you had taken part of my privacy. Times have changed. I'm not your incapable girl any more. I'm growing up and I don't always want the same things that you did when you were younger.

However, weaker writers were much less assured in managing to use sentence boundaries and within-sentence connectivity to support the communication of their ideas. The extracts below are typical of the writing of many of these weaker writers. As with primary school writers, the tendency to chain ideas together using co-ordinating conjunctions is evident in the first extract, whilst the second extract uses subordination more heavily, particularly the repeated pattern of beginning a sentence with a subordinate clause:

Then I ran, and ran back to jane and she was sat crying on the grass. we took her to first Aid. they gave her a plaster, then finally we made some sand castles and after a while I heard a noise. it sounded like the ringing of the school bells so jane and I ran to our teacher and she took us back to the class room to do some colouring. I remember colouring a picture of a bird and I gave it to jane and she coloured a picture of a rabbit and gave it to me. Time pasted and it was nearly time to go home so jane and I helped our teacher Mrs. butler to put the colouring crayons away then sat at our places and waited for our mums to pick us up.

If I had known what lay ahead I would've stopped him from leaving, but alas he went upstairs to get ready for work. I remember still lying there watching TV thinking it was just another normal day. While my dad was getting ready my mum came in and told me to watch educational programmes. When I turned over the channel I got stuck into watching El nombre.

The parallel finding, illustrated in Table 3, that good writing is associated with lower use of finite verbs when compared with weak writing was mirrored in the year group data. The better writing in both year 8 and year 10 used fewer finite verbs, and comparing the year 8 sample with the year 10 sample reveals a statistically significant difference $(p=0.01)$ in finite verb frequency between the two year groups. The qualitative analysis indicates that sentence structure in good writing is syntactically elaborated beyond simple subject-verb patterns, for example, by greater use of adverbs or non-finite clauses, or expanded noun phrases.

However this was an adventure and I stepped off the coach, anxious to explore the house, which stood so tall, like a king proudly viewing his territory. 
I stood directly in front of two gaping giants; the elaborate designs on the doors were statements of authority in themselves. The intricate details in the patterns were absolutely amazing.

The data entry process had collated all the subordinators used in the writing samples and a further analysis of subordinate clauses was undertaken by categorizing the subordinators and tallying how often each subordinator was used in writing of different quality. This revealed that not only do good writers use less subordination but they also use subordinators differently. The table below shows the subordinators found in different quality writing, ranked by frequency with the most frequently used at the top of the table.

\begin{tabular}{|l|l|l|}
\hline Good & Average & Weak \\
\hline that & that & [that] \\
[that] & [that] & that \\
as & as & when \\
which & when & because \\
if & which & as \\
when & if & if \\
who & because & which \\
because & what & who \\
what & who & what \\
how & where & where \\
where & how & like \\
so [that] & so [that] & so [that] \\
& like & how \\
\hline
\end{tabular}

Table 4: Patterns of Usage of Subordinators

Considering the 13 most commonly-used subordinators in the whole sample, the following usage patterns are evident:

good writing uses that more than weak writers who conversely use zero that more than good writers;

a as and how are used more frequently in good writing

- when, because, and if are used more frequently in weak writing than in good writing;

u the non-standard use of like as a subordinator is a strong feature in weaker writing but used very little in the writing.

Analysis of the less commonly-used subordinators suggests that there is a tendency for the subordinators before; although; while; and how much to be more common in good writing. However, care has to be taken with this data as the frequencies are much lower and the patterns thus less reliable. Further studies might usefully focus exclusively on patterns of subordination in texts of differing quality and could provide a more fine-grained analysis of usage, including greater discrimination between types of subordinator (for example between 'as' used temporally or causally). 
In summary, the analysis of clause patterns presented here illuminates some interesting developmental trajectories: older writers and more able writers do not continue to increase their use of subordination and complex sentences, as is the case with developing younger writers. Instead, they develop a greater facility for using simple sentences, and a greater facility for expansion of ideas within the sentence.

\section{Variety in sentence openings}

The study also sought to investigate whether there were developmental patterns in the ways writers began their sentences, and managed thematic links with what has gone before. The data indicates the strong tendency of weaker writes to repeat the syntactical pattern of using a subject opening. The better the piece of writing, the less likely it is to use a subject opening to a sentence. This appeared to be more strongly related to writing competence than to age as there was no statistically significant difference in subject sentence starts between year 8 and year 10.

\begin{tabular}{|l|l|l|l|}
\hline per 100 words & & Mean & Statistical significance \\
\hline Number of & good & 4.17 & \multirow{3}{*}{$0.010^{*}$} \\
\cline { 2 - 3 } $\begin{array}{l}\text { sentences opening with } \\
\text { a subject }\end{array}$ & average & 4.36 & \\
\cline { 2 - 3 } & weak & 4.74 & \multirow{2}{*}{0.146 (no sig) } \\
\cline { 2 - 3 } & year 8 & 4.54 & \\
\cline { 2 - 3 } & year 10 & 4.31 & \\
\hline
\end{tabular}

Table 5: Differences in number of sentences opening with a subject

The example below is typical of the weaker writing, using predominantly subject starts to sentences. The qualitative analysis indicates that this repetitive pattern is frequently reinforced by repetition of a pronoun, in this case the first person pronoun:

It was a day l'd never forget. I'd been asleep and for some reason I wok up in the middle of the night. I smelt burning. I ran in to wake my mum and dad because I thought our house was on fire. We searched our home high and low but we didn't find anything. I ran outside to see Were else it could be. I looked around and I saw that it was my best friend's house (next door). I shouted to my mum to phone the police and fire biegrade. While she done that I ran to see if any one was home. I banged on the door trying to get them up. I managed to wake them up. We went outside then into my house.

There were no statistically significant differences in the use of a finite subordinate clause to open a sentence: writers in each age group and at each ability level used finite subordinate clauses, though the raw data indicates that weak writers had a slight tendency to use them more. The qualitative data suggests that the use of timerelated subordinators such as 'when' frequently introduce the subordinate clause in weaker writing, and this is an area which would merit further quantitative analysis. The use of an adverbial to begin a sentence, however, appears to be a more discriminating marker of development. The best writers in year 8 were more likely to begin a sentence with an adverbial (at statistically significant level: $p=0.022$ ), but in year 10 , the average writers made 
more use of adverbials. The trend for higher achievers in year 8 and middle achievers in year 10 to use adverbials produces an overall result of no significant difference. This appears to suggest that using an adverbial is a development feature: writers move from sentence openings with a subject to varying the opening with the use of an adverbial, but more able writers have a greater repertoire of opening strategies and decrease their use of adverbials. The overall sample means support this hypothesis as the mean for average writing is higher than that for either good or weak writing.

\begin{tabular}{|l|l|l|l|}
\hline Per 100 words & & Mean & Statistical significance \\
\hline \multirow{2}{*}{$\begin{array}{l}\text { Adverbial sentence } \\
\text { opening: Year 8 }\end{array}$} & good & 1.25 & \multirow{2}{*}{$0.022^{*}$} \\
\cline { 2 - 3 } & average & 1.05 & \\
\cline { 2 - 3 } & weak & 0.86 & \multirow{2}{*}{0.434} \\
\hline \multirow{2}{*}{$\begin{array}{l}\text { Adverbial sentence } \\
\text { opening: Year 10 }\end{array}$} & good & 0.95 & \\
\cline { 2 - 3 } & average & 1.22 & \multirow{2}{*}{0.085} \\
\cline { 2 - 3 } & weak & 0.97 & \\
\hline \multirow{2}{*}{$\begin{array}{l}\text { Adverbial sentence } \\
\text { opening: } \\
\text { whole sample }\end{array}$} & good & 1.12 & \\
\cline { 2 - 3 } & average & 1.17 & 0.92 \\
\cline { 2 - 3 } & weak & & \\
\hline
\end{tabular}

Table 6: Differences in usage of adverbials to open a sentence

The use of a non-finite clause to open a sentence was a feature of better writing, with the likelihood of a non-finite clause sentence start increasing with the quality of writing. The pattern was evident in both year 8 and year 10 but it was only significant in year $10(p=0.040)$, suggesting that the non-finite clause might be one of the increased repertoire of sentence openings in good writing which accounts for the lower incidence of the adverbial in good writing in year 10 .

Examples of the non-finite openings found in good writing included the following:

After looking at all the possibilities, ...

Thrust into a cold and cruel world, ...

Being an only child, ...

Working in these conditions, ...

To solve the problem, ...

One further aspect of syntactical variety which is linked to choices made about how to start a sentence was the presence of subject-verb inversions, which were more frequent in good writing $(p=0.021)$. In many cases, the inversion was achieved through using an adverbial start which permitted the subsequent inversion, and allowed the writer to alter where the emphasis in the sentence fell. The quantitative analysis shows that altering the syntactical structure of the sentence through a subject-verb inversion was also a marker of good writing, with the presence of subject-verb inversions declining with decreasing quality. Examples of these inversions included:

Over one of the bed knobs hung a school tie... 
There, five feet above me was my bed...

Here is truly the roof of the world.

Ahead were the dim lights of the manor.

Analysing variety in sentence openings has provided a valuable insight into developmental patterns in control of the sentence. The predominance of standard subject sentence openings in weaker writers may be a reflection of typical speech patterns or because the Subject Verb sentence is the most basic sentence pattern. It is clear, however, that development is marked by an increasing ability to alter this basic syntactic pattern to create a different emphasis or effect - the better writers manipulate or design their sentences to foreground important information or to direct their readers to a way of interpreting the sentence. The data suggests that the adverbial is the first developmental advance in this respect, with better writers increasing their repertoire to include non-finite clause sentence openings.

\section{Discussion}

The findings from this study suggest that developmental trajectories in mastery of the sentence in older school writers are more closely aligned to writing competence than to age, as the data analysis reveals far more statistically significant differences between the writing of writers of different ability than between the writing of writers of different ages. However, in broad terms, the developmental patterns identified between weak and good writers are mirrored by age. One implication of this is that, whilst it is reasonable to expect writers to become increasingly competent in their control of the sentence as they get older, the principal developmental trajectory is from weak to good writing.

The study also underlines the insights that can be gained from adopting linguistic perspectives in the consideration of writing development, particularly when numerical data is exemplified by qualitative data. There is emerging evidence here that linguistic analysis can indeed support 'understanding of the developmental processes' (Kress 1994:3) in learning to become a better writer, and can offer a 'linguistic theory of good structures' (Collins and Gentner 1980: 53) at the level of the sentence. Below is a diagram which is an attempt to represent a model of linguistic development in the use of the sentence.

\begin{tabular}{|c|c|c|c|c|}
\hline \multicolumn{5}{|c|}{ A MODEL OF LINGUISTIC DEVELOPMENT OF THE SENTENCE IN SECONDARY PUPILS } \\
\hline & & \multicolumn{2}{|l|}{ YOUNGER } & OLDER \\
\hline & & WEAK & AVERAGE & GOOD \\
\hline \multirow{2}{*}{ 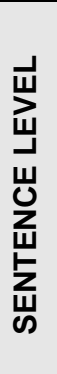 } & $\begin{array}{l}\text { Length and } \\
\text { control }\end{array}$ & $\begin{array}{l}\text { shorter words } \\
\text { shorter sentences } \\
\text { similar sentence lengths } \\
\text { some coherence lapses }\end{array}$ & fewer coherence lapses & $\begin{array}{l}\text { longer words } \\
\text { longer sentences } \\
\text { contrasting sentence lengths } \\
\text { sentence patterning for effect }\end{array}$ \\
\hline & Clauses & $\begin{array}{l}\text { more multiply-claused sentences } \\
\text { more compound sentences than } \\
\text { complex } \\
\text { use of common temporal and }\end{array}$ & $\begin{array}{l}\text { similar nos. of compound and } \\
\text { complex sentences }\end{array}$ & $\begin{array}{l}\text { some simple sentences } \\
\text { fewer compound than complex } \\
\text { sentences; } \\
\text { use of wider repertoire of }\end{array}$ \\
\hline
\end{tabular}




\begin{tabular}{|c|c|c|c|}
\hline & $\begin{array}{l}\text { causal subordinators (when; } \\
\text { because; if) } \\
\text { use of non-standard 'like' }\end{array}$ & & $\begin{array}{l}\text { subordinators (eg as; how; before; } \\
\text { although; while; therefore) } \\
\text { no use of non-standard 'like' }\end{array}$ \\
\hline $\begin{array}{l}\text { Sentence } \\
\text { expansion }\end{array}$ & heavy use of finite verbs & $\begin{array}{l}\text { more use of adjectives and adverbs } \\
\text { for expansion }\end{array}$ & $\begin{array}{l}\text { fewer finite verbs } \\
\text { more non-finite clauses, particularly } \\
\text { present participle clauses }\end{array}$ \\
\hline $\begin{array}{l}\text { Syntactical } \\
\text { variety }\end{array}$ & $\begin{array}{l}\text { reliance on subject to open } \\
\text { sentence } \\
\text { few subject-verb inversions } \\
\text { few passive constructions }\end{array}$ & $\begin{array}{l}\text { greater use of adverbials to open } \\
\text { sentences, as well as subject }\end{array}$ & $\begin{array}{l}\text { greater use of non-finite clauses } \\
\text { and adverbials to open sentences } \\
\text { more subject-verb inversions } \\
\text { greater use of passive } \\
\text { constructions }\end{array}$ \\
\hline
\end{tabular}

Figure 1: A Model of Linguistic Development of the Sentence

Potentially, there are some significant theoretical implications of this model. Firstly, it is evident that for weaker writers (and to a lesser extent, younger writers) there is a dominance of linearity and temporality governing sentence structure. The predominance of Subject Verb sentences, of temporal subordinators, including the possible higher use of 'when' subordinate clauses to start sentences, and of compound sentences chained by 'and' points to writers who remain at the knowledge-telling stage (Bereiter and Scardamalia 1987), more concerned with the content they wish to capture on the page, than with the rhetorical effects that could be achieved through different structures. It may also be that this linearity and temporality reflects writing that is close to the speech-writing interface, and that these weaker writers are less assured in managing the specific rhetorical demands of writing partly because of the influence of their oracy experiences.

A second theoretical implication of this model is that all the developmental characteristics of the able writers signal that design ability is a key marker of development. Counterpointing long sentences with short sentences, using short sentences for effect, and altering the syntactical starting point of a sentence to give weight to different ideas use linguistic structures to create meaning through form as well as content. Better writers shape and craft to communicate, and to match their message with the rhetorical purposes, and the implied reader, of the text. Within the field of writing pedagogy, this intrinsic relationship between form and content has generally been understood. McCormick Calkins (1990: 74), for example, recognised that 'composing a text has everything to do with finding the meaning in the moments, and then with deliberately shaping a text that conveys that meaning'. However, there has been limited articulation of precisely how writers improve and develop their ability to craft and shape, just as Bereiter and Scardamalia (1987) do not describe how a child moves from knowledge-telling to knowledgetransforming. Equally, cognitive models of writing which regard the act of translation from idea to words on a page as unproblematic do not seem to fully acknowledge the design demand of effective writing as opposed to mere production of text.

Applebee's (2000) argument that studies such as those of Hunt (1965) and Loban (1976) had failed to find evidence of a developmental sequence in acquiring syntactic structures, and that development is less about new structures and more about 'an increasing degree of structural complexity' (2000:97) is both confirmed and disconfirmed by this research. On the one hand, the linguistic model of sentence development presented above suggests that there are syntactical structures whose appearance appears to be related to development. For 
example, the use of an adverbial to begin a sentence appears to be the first stage in developing variety in sentence openings, whilst the use of a non-finite clause appears to be at a later stage. On the other hand, there is much in this study to support Applebee's view that development is about increasing structural complexity: the decrease in finite verb frequency to accommodate greater expansion within the sentence, the use of subject-verb inversions and passives, the patterning for effect of sentence lengths are principally about better deployment of syntactical structures already within the writer's repertoire.

However, there remains scope for further theoretical development, of the methodological processes, the model itself and the implications of the model. The methodology required decisions to be made about linguistic constructions to be analysed, the size and nature of the sentence analysis sample, and the use of national assessments to determine 'quality' of writing in the sample. These would all benefit from further replication studies or confirmatory studies using alternative methodologies. Equally, the model itself could be extended through further linguistic studies of children's writing, by exploring, for example, the use of nouns and pronouns, the length of noun phrases, and the types of subordinators used to open sentences. Secondly, further research might address the issue of temporality and linearity in weaker writers to ascertain a clearer understanding of the factors which influence this tendency. Crucially, given that design ability is such an important marker of development, it is important to develop a more adequately theorised understanding of the role explicit and implicit knowledge plays in the cognitive and linguistic processes used by writers. In particular, are design choices at the level of the sentence, conscious or unconscious choices, and to what extent is design ability influenced by metalinguistic awareness?

As Collins and Gentner (1980) predicted, the consequence of establishing a linguistic theory of writing development is significant for both pedagogy and policy regarding writing in the secondary school. At the level of policy and curriculum documentation, there appears to be an over-emphasis on complex sentences, but with little corresponding understanding of what development might be. For example, the developmental pathway implied by the National Curriculum for English is unclear. It specifies that primary school writers should be taught 'the grammar of complex sentences' (DfEE 2000:29), whilst secondary school writers should be taught 'the structure of phrases and clauses and how they can be combined into complex sentences' (DfEE 2000:38). The Framework for Teaching English, (DfES 2001) a non-statutory but high-status document outlining teaching objectives for children aged 12, 13 and 14, is considerably more detailed about sentence construction, and does include references to short sentences for effect and expanding noun phrases. Nonetheless, the key Sentence Level objective for the first two years of secondary education relates to complex sentences. In year 7 (11-12 year olds), pupils should be taught to 'extend their use and control of complex sentences' DfES 2001:22); and in year 8 (12-13 year olds), they should 'combine clauses into complex sentences' (DfES 2001:26). This research suggests that only the weakest writers have difficulty controlling complex sentences, and that rather than learning to combine clauses, some writers would benefit from learning when not to combine clauses.

Pedagogically, this model of development in mastery of the sentence may help teachers to intervene more strategically to support writers at different stages of competence. For example, weaker writers may need focused support in managing complex ideas in long sentences, which might include greater use of subordination rather 
than co-ordination, but which also might include segmenting ideas from one sentence into two sentences. Able writers, on the other hand, might benefit from discussion about the different ways to start a sentence. Whilst it is clear how the linguistic model might inform the goal of teaching 'to achieve greater control of textual features' (Morgan 1997:67), the qualitative analysis and exemplification presented here is a reminder that the linguistic structures per se have no intrinsic merit: complex sentences are not necessarily good sentences; subject-verb inversions are not always effective; and short sentences do not always have impact. Writing is, first and foremost, a communicative act, created in a context, and linguistic structures are meaning-making resources to support that communicative act. The real power of looking at syntactical patterns in sentences is in making connections for the learner between what a text means and how it achieves that meaning. Both are important and mutually complementary. 


\section{References:}

Alamargot, D. and Chanquoy, L. (2001) Through the Models of Writing Dordrecht: Kluwer Academic Publishers Applebee, A. (2000) 'Alternative Models of Writing Development' in Indrisano, R. and Squire, J. (eds) Perspectives on Writing: Research, Theory and Practice Newark: IRA

Arnold, R. (1991) Writing Development Buckingham: Open University Press.

Bereiter, C. and Scardamalia, M. (1987) The Psychology of Written Composition Hillsdale, NJ: Lawrence Erlbaum Associates

Berninger, V. W. and Swanson, H. L. (1994) Modification of the Hayes and Flower model to explain beginning and developing writing in Butterfield, E. (ed) Advances in Cognition and Educational Practice Vol 2 Children's writing: towards a process theory of development of skilled writing Greenwich, CT: JAI Press.

Berninger, V. W. Fuller, F and Whittaker, D (1996) A Process model of Writing Development across the Lifespan Educational Psychology Review 8 (3) 193-217

Brown, G. and Yule, G. (1983) Discourse Analysis Cambridge: Cambridge University Press

Cleland, A. A. and Pickering. M.J. (2006) Do Writing and Speaking Employ the same Syntactic Representations? Journal of Memory and Language, 54, 185-198

Collins, A. and Gentner, D (1980) A Framework for a Cognitive Theory of Writing, in Gregg, L.W. and Steinberg, E. R Cognitive Processes in Writing New Jersey: Lawrence Erlbaum Associates, Hillsdale.

Czerniewska, P. (1992) Learning about Writing Oxford: Blackwell

Department for Education and Employment (DfEE) (2000) English: The National Curriculum for England London: DfEE,QCA

DfES (2001) Framework for Teaching English: Years 7, 8 and 9 London: DfES

Hudson, R. (2004) Why Education needs Linguistics' Journal of Linguistics 40.1 105-130

Hunt, K. (1965) Grammatical Structures written at Three Grade Levels Research Report 3. Urbana: NCTE Kress, Gunter. (1994) Learning to Write London: Routledge

Lagemann, E. C. (2002) An Elusive Science: The Troubling History of Education Research Chicago: University of Chicago Press

Leech, G.N. and J. Svartvik. (1975) A communicative grammar of English London: Longman

Loban, W. (1976) Language development: Kindergarten through grade twelve Research Report 18. Urbana, IL: National Council of Teachers of English.

Maun, I. and Myhill, D (2005) Text as Design, writers as designers. English in Education 39/2 5-21

McCormick Calkins, Lucy. (1990) Living Between the Lines New Hampshire: Heinemann

Morgan, W. (1997) Critical Literacy in the Classroom. London: Routledge

Massey, A. J. \& Elliott, G. L. (1996). Aspects of Writing in 16+ English Examinations between 1980 and 1994.

Occasional Research Paper 1. Cambridge: University of Cambridge Local Examinations Syndicate.

Myhill, D.A. (1999) Writing Matters English in Education 33/3 70-81

Perera, K. (1984) Children's Writing and Reading: Analysing Classroom Language Oxford: Blackwell

Qualifications and Curriculum Authority (QCA) (1999) Improving Writing London: QCA

Quirke, R. Greenbaum, S. Leech, G.N. and Svartvik, J (1985) A Comprehensive Grammar of the English

Language London: Longman

Sharples, M. (1999) How We Write: Writing as Creative Design London: Routledge 